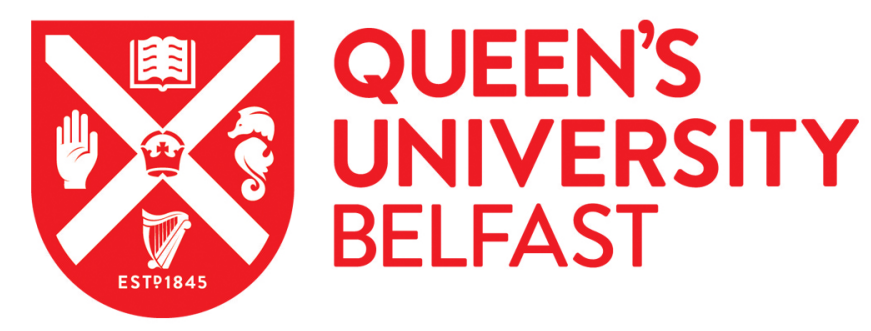

\title{
Examining effects of ontogenic microplastic transference on Culex mosquito mortality and adult weight
}

Al-Jaibachi, R., Cuthbert, R. N., \& Callaghan, A. (2019). Examining effects of ontogenic microplastic transference on Culex mosquito mortality and adult weight. Science of the Total Environment, 651(1), 871-876. https://doi.org/10.1016/j.scitotenv.2018.09.236

Published in:

Science of the Total Environment

Document Version:

Peer reviewed version

Queen's University Belfast - Research Portal:

Link to publication record in Queen's University Belfast Research Portal

Publisher rights

Copyright 2018 Elsevier.

This manuscript is distributed under a Creative Commons Attribution-NonCommercial-NoDerivs License

(https://creativecommons.org/licenses/by-nc-nd/4.0/), which permits distribution and reproduction for non-commercial purposes, provided the author and source are cited.

\section{General rights}

Copyright for the publications made accessible via the Queen's University Belfast Research Portal is retained by the author(s) and / or other copyright owners and it is a condition of accessing these publications that users recognise and abide by the legal requirements associated with these rights.

Take down policy

The Research Portal is Queen's institutional repository that provides access to Queen's research output. Every effort has been made to ensure that content in the Research Portal does not infringe any person's rights, or applicable UK laws. If you discover content in the Research Portal that you believe breaches copyright or violates any law, please contact openaccess@qub.ac.uk. 
Examining effects of ontogenic microplastic transference on Culex mosquito mortality and adult weight

Rana Al-Jaibachi ${ }^{1}$, Ross N. Cuthbert ${ }^{1,2}$, Amanda Callaghan ${ }^{1 *}$

${ }^{1}$ Ecology and Evolutionary Biology, School of Biological Sciences, University of Reading, Harborne Building, Reading RG6 6AS, England

${ }^{2}$ Institute for Global Food Security, School of Biological Sciences, Medical Biology Centre, Queen’s University Belfast, Belfast BT9 7BL, Northern Ireland

*Corresponding author: e-mail, a.callaghan@reading.ac.uk 


\section{Abstract}

Microplastics (MPs) continue to proliferate and pollute aquatic and terrestrial environments globally. The impacts of MP pollution on ecosystems and their functioning remain poorly quantified, with most research hitherto focusing on marine ecosystems. There is a paucity of information on the impacts of MPs in freshwater ecosystems, despite the broad range of pathways through which MPs can proliferate and the extensive range of species which actively ingest MPs in these systems. Of particular interest are organisms that bridge aquatic and terrestrial habitats. The present study thus examines the uptake, ontogenic transference and effect of different concentrations $\left(0,50,100\right.$ and $\left.200 \mathrm{MPs} \mathrm{mL}^{-1}\right)$ and sizes $(2$ and $15 \mu \mathrm{m})$ of polystyrene MPs between aquatic and terrestrial life stages of Culex pipiens complex mosquitoes. Both 2 and $15 \mu \mathrm{m}$ MPs transferred from the aquatic larval to terrestrial adult stage of Culex mosquitoes, and uptake correlated tightly with initial exposure concentration. However, neither concentration nor size of MPs significantly influenced mortality rates between the aquatic larval and terrestrial adult stage. There was also no impact of MPs on the weight of emerging mosquito adults. We thus demonstrate that MPs can be transferred ontogenically through organisms with complex life histories, presenting a potential pathway for dispersal of MPs into terrestrial environments. We also show that MPs exposure does not affect mortality rates between life stages of freshwater Culex populations. This suggests that MPs do not impact nutritional uptakes, with unhampered development to adulthood facilitating subsequent dispersal of MPs aerially and between freshwater and terrestrial habitats.

Keywords: microplastics, mosquitoes, ontogenic transference, habitat transference 


\section{Introduction}

Microplastics (MPs) continue to proliferate in marine, freshwater and terrestrial ecosystems, with biotic impacts frequently unknown (Sighicelli et al., 2018). Microplastic pollution has been detected from the poles to the deep ocean, and more recently in bottled drinking water (Mason et al., 2018; Wagner and Lambert, 2018). Whilst there is little doubt over the enormity of plastic and MP pollution in scale, the vast majority of research has concentrated on marine environments whilst neglecting other ecosystems (Redondo-Hasselerharm et al., 2018; Wagner and Lambert, 2018). To date there is a paucity of information on the impacts of MPs in freshwater ecosystems, despite the broad range of pathways through which MPs can proliferate (Mason et al., 2016), and the extensive range of species which actively ingest MPs in these systems (Canniff and Hoang, 2018; Imhof et al., 2016, 2013; Nel et al., 2018; Qu et al., 2018).

Microplastics have been defined as plastic particles of 5mm or less in size (Imhof et al., 2013; Eriksen et al., 2014). This is a broad definition as MPs manifest in a variety of forms, such as fibres, pellets and cosmetic beads, which all routinely enter the environment (Watts et al., 2014). Microplastics differ in their chemical composition, and can consist of various polymers such as polypropylene, polyethylene and polystyrene (Andrady and Neal, 2009; Rocha-Santos and Duarte, 2014). Furthermore, MPs can either be primary or secondary in origin, with the former released directly into the environment as MPs, and the latter having degraded over time to reach the MP size class (Moor, 2008; Barnes et al., 2009). Despite such inherent variation, there has been little work to compare differential impacts of the varied types of MPs on recipient organisms.

Movement of MPs through terrestrial and aquatic environments has been investigated, and several pathways have been suggested. For example, movement through the air due to wind (Dris et al., 2016) or directly through water courses from wastewater treatment plants into 
rivers and eventually the marine environment (Mason et al., 2016; Wagner and Lambert, 2018). Rivers can also deliver MPs into lakes, where they can be found in high concentrations and presumably fall into the sediment (Vaughan et al., 2017). In North America the highest MP concentrations were found in Lake Ontario-Erie, with an average range of $90000-6700000$ items $\mathrm{km}^{-2}$ (Fischer et al., 2016). In Europe, Lake Geneva contained the highest MP concentration with a mean of $220000\left( \pm \mathrm{SD}: \pm 160000\right.$ items $\mathrm{km}^{-2}$ (Eriksen et al., 2013), and in Asia, Lake Taihu contained a range of $10000-6800000$ items $\mathrm{km}^{-2}$ (Su et al., 2016).

Given the densities of MPs in freshwater ecosystems, it is likely that they will be ingested by aquatic organisms, and, in turn, probable that they will be transferred up through the food chain (Cole et al., 2013; Sussarellu et al., 2016; Scherer et al., 2017; Redondo-Hasselerharm et al. 2018). Laboratory experiments have demonstrated the uptake of MPs, and it is well established that they are ingested by many invertebrates in both freshwater and marine environments (Imhof et al., 2013; Al-Jaibachi and Callaghan, 2018). However, considerations of whether MPs can be transmitted by means of ontogenic transference, i.e. between life stages within an individual, have remained scarce. Insects comprise an important component of freshwater environments and are often highly abundant (Macadam and Stockan, 2015). Many insects have complex life histories, consisting of successive aquatic and terrestrial stages. Examples of such insects are stoneflies, damselflies, midges and mosquitoes, most of which are eaten by birds in their terrestrial stage. Thus, ontogenic transference of MPs presents a further pathway for MPs to enter new ecosystems from aquatic environments, with the potential to enter organisms that do not feed on the aquatic stages of freshwater or marine organisms.

The present study was undertaken to determine whether MPs could transfer between insect life stages of species with complex life histories, and could affect survival and adult size, which is linked to fecundity (Takken et al., 2013). Mosquitoes (Diptera: Culicidae) are ideal for this study since they go through four feeding larval instars, a non-feeding pupal stage and finally 
emerge into a flying adult that feeds on nectar and/or vertebrate blood depending on the sex and species. Here, we investigate whether mosquito larvae are able to ingest $2 \pm 0.2$ and $15 \pm$ $1.1 \mu \mathrm{m}$ in diameter fluorescent polystyrene beads, and whether consumption is concentrationdependent. Fluorescent beads were selected to enable MPs to be easily detected in the nonfeeding stages and also to allow an investigation of location within the body during metamorphosis. Culex pipiens complex mosquitoes were selected for this study because they exhibit a global distribution and colonise a broad range of aquatic habitats, such as stream pools, lake edges, marshes and shallow permanent ponds, alongside both natural (phytotelmata) and artificial containers (Townroe and Callaghan, 2015). The group is also known to be an important food source for birds and other terrestrial organisms in the adult stage (Dow et al., 1994). We hypothesise that: (1) MPs will move ontogenically from larval to pupal stages, and subsequently into adult mosquito stages, and that transference is both MP densityand size-dependent; (2) uptake of MPs will reduce the survivability of larval mosquitoes to the adult stage; (3) exposure to MPs will affect the nutrition and thus development of larval mosquitoes, resulting in smaller-sized adults upon emergence.

\section{Materials and methods}

\subsection{Preparation of microplastics (MPs)}

Two types of MPs were used: a $2 \pm 0.2 \mu \mathrm{m}$ fluorescent yellow-green carboxylate-modified polystyrene (density $1.050 \mathrm{~g} \mathrm{~cm}^{-3}$, excitation $470 \mathrm{~nm}$, emission $505 \mathrm{~nm}$; Sigma-Aldrich, UK) and a $15.45 \pm 1.1 \mu \mathrm{m}$ fluorescent dragon green polystyrene (density $1.06 \mathrm{~g} \mathrm{~cm}^{-3}$, excitation 480 nm, emission $520 \mathrm{~nm}$; Bangs Laboratories Inc., USA).

The $2 \mu \mathrm{m}$ MPs were stored as a stock suspension $\left(2.5 \mathrm{mg} \mathrm{mL}^{-1}\right)$ in distilled water and mixed using a vortex (Whirlimixe Cyclon, UK) prior to dilutions. The $15 \mu \mathrm{m}$ MPs were also stored as stock suspension ( $1 \%$ solid) polystyrene microspheres. Particles were washed prior to use 
by adding $1 \mathrm{~mL}$ from the stock solution into a $1.5 \mathrm{~mL}$ Eppendorf tube and then centrifuging at $9000 \mathrm{rpm}$ for $10 \mathrm{~min}$. The supernatant was discarded and $1 \mathrm{~mL}$ of distilled water was added. The solution was then resuspended by using the vortex and centrifuged again at the same speed and duration. This process was repeated two more times.

\subsection{Mosquito colonies}

Larvae of the C. pipiens mosquito complex were obtained from colonies reared at the University of Reading, UK following the methodology of Cuthbert et al. (2018). This colony originated from individuals collected in Cyprus in 2005 by Dr A. Callaghan and have been reared in laboratory conditions since then. Adult C. pipiens were fed overnight twice a week with defibrinated horse blood (TCS Biosciences, UK) using artificial membrane feeder (Hemotek, UK). Cotton pads soaked in $10 \%$ sucrose solution were provided for additional sustenance.

\subsection{Experimental protocols}

We exposed C. pipiens larvae to one of two MP sizes (2 and $15 \mu \mathrm{m})$ under one of four concentrations $\left(0,50,100\right.$ and $\left.200 \mathrm{MP} \mathrm{mL}^{-1}\right)$ in a crossed design in the same laboratory where the colonies are maintained $\left(25 \pm 2{ }^{\circ} \mathrm{C}, \mathrm{RH} 70 \pm 5 \%, 16: 8\right.$ light:dark $)$. In each of five replicates per treatment group, ten third instar C. pipiens larvae were placed in a glass beaker $(60 \times 80$ $\mathrm{mm}$ ) filled with $120 \mathrm{~mL}$ of tap water and $100 \mathrm{mg}$ of pelleted guinea pig food for sustenance. Treatments were assigned randomly to a position on the laboratory bench to reduce experimental error. Microplastic concentrations were quantified at the start and the end of the experiment by taking $5 \times 1 \mathrm{~mL}$ from different points of each beaker (Table $\mathrm{S} 1$ ).

\subsection{Uptake and ontogenic transference}


One individual was randomly removed from each beaker once all mosquitoes in the beaker had moulted into the $4^{\text {th }}$ instar, and again when they pupated or emerged as adults. All samples were then washed twice with distilled water to remove MPs from the surface of the mosquito and placed in separate $1.5 \mathrm{~mL}$ Eppendorf tubes, before being stored at $-20{ }^{\circ} \mathrm{C}$ prior to examination.

Microplastics were extracted from mosquitoes by homogenization and filtration. Mosquitoes were homogenized using a glass pestle in Eppendorf tubes containing $500 \mu \mathrm{L}$ distilled water. Individuals treated with $2 \mu \mathrm{m}$ MPs were filtered through a nucleopore track-etched membrane (Whatman, UK) of $<1 \mu \mathrm{m}$ and $25 \mathrm{~mm}$ dia.. Those exposed to $15 \mu \mathrm{m}$ MPs were filtered through a nucleopore track-etched membrane (Whatman, $\mathrm{UK}$ ) of $<10 \mu \mathrm{m}$ and $25 \mathrm{~mm}$ dia. using a glass vacuum filter holder connected to a manual air pump. The MPs captured by both filters were quantified under a $20 \times$ epi-fluorescent microscope (Zeiss Axioskop, USA). Adults were further dissected under a binocular stereo microscope $(0.7 \times-4.5 \times)$ to extract the gut and quantify the numbers of MPs under the epi-fluorescent microscope (Coleman et al., 2007).

\subsection{Mortality rates}

Mortality of successive stages was monitored and recorded daily over the course of the 12 day experimental period. We thus deduced overall proportional survival to the adult mosquito stage in C. pipiens.

\subsection{Emerging adult weights}

Emerging adult mosquitoes from each treatment were weighed using a microbalance (Thermo Cahn, USA), then examined under the epi-fluorescent microscope to ensure that no MPs were attached to the body.

\subsection{Statistical methods}


All data were analyzed using the statistical software R v3.4.2 (R Development Core Team, 2017). Quantities of MPs in larval, pupal and adult Culex mosquito stages were analysed separately using generalised linear models (GLMs) assuming a quasi-Poisson error distribution as counts were found to be overdispersed compared to degrees of freedom. Microplastics were absent from all control groups, and so we excluded this treatment from statistical analyses here. The effects of MPs on proportioned survival of Culex from the larval to the adult stage were then analysed separately using GLMs assuming a quasi-binomial error distribution. Then, the

effects of MP treatments on adult weights were analysed using ANOVA following $\log 10$ transformation to meet normality and homoscedasticity assumptions (Shapiro-Wilk test, $p>$ 0.05; Bartlett's test, $p>0.05$ ). In all models, we initially incorporated 'concentration' and 'MP size' of MPs as explanatory variables factorially. We then performed backward stepwise deletion of insignificant terms and interactions to facilitate the most parsimonious model fits (Crawley, 2007). We performed post hoc Tukey's comparisons where terms significantly affected a response variable at the $95 \%$ confidence level (Lenth, 2016).

\section{Results}

No MPs were found in control group replicates. Microplastics of both sizes were found in larval, pupal and adult life stages of mosquitoes, however abundances were strongly related to initial exposure concentration and MP size at each ontogenic stage. Abundance of MPs in larval mosquitoes was significantly influenced by initial exposure concentrations $\left(\mathrm{F}_{(2,27)}=84.55, p<\right.$ 0.001), with quantities of MPs significantly higher across all increasing concentration increments (all $p<0.001$; Figure 1a), and abundances up to a maximum of 255.8 ( \pm SD: \pm 8.7 ) MP larva ${ }^{-1}$. Significantly greater quantities of $2 \mu \mathrm{m}$ MPs were found in larval C. pipiens than $15 \mu \mathrm{m} \operatorname{MPs}\left(F_{(1,26)}=28.53, p<0.001\right)$. Furthermore, there was a significant interaction effect between 'concentration' and 'MP size' $\left(F_{(2,24)}=6.44, p=0.006\right)$, reflecting emergent effects between the variables (Figure 1a). Whilst there were no significant differences in MP quantities 
in Culex larvae at $50 \mathrm{MPs} \mathrm{mL}^{-1}$ or $100 \mathrm{MPs} \mathrm{mL}^{-1}$ between the two MP size classes (both $p>$ 0.05), uptake of the smaller $2 \mu \mathrm{m}$ MPs was significantly higher at concentrations of $200 \mathrm{MPs}$ $\mathrm{mL}^{-1}$ than $15 \mu \mathrm{m}$ MPs at the same concentration $(p<0.001)$.

For pupae, exposure concentration also had a significant effect on MP abundance in C. pipiens $\left(F_{(2,27)}=4.56, p=0.02\right)$, with abundances up to a maximum of $54.8( \pm \mathrm{SD}: \pm 54.2) \mathrm{MP}_{\mathrm{pupa}}{ }^{-}$ 1. Whilst there were similarities in uptake between $50 \mathrm{MPs} \mathrm{mL}^{-1} v s 100 \mathrm{MPs} \mathrm{mL}^{-1}(p=0.31)$, and $100 \mathrm{MPs}_{\mathrm{mL}}^{-1}$ vs $200 \mathrm{MPs}_{\mathrm{mL}}^{-1}(p=0.28)$, MP abundances in pupae were significantly greater at $200 \mathrm{MPs} \mathrm{mL}^{-1}$ compared to $50 \mathrm{MPs} \mathrm{mL}^{-1}(p=0.01)$. Moreover, significantly lower quantities of $15 \mu \mathrm{m}$ MPs were found in pupae as compared to $2 \mu \mathrm{m}$ MPs $\left(F_{(1,26)}=133.25, p<\right.$ 0.001; Figure 1b), and this effect was consistent across exposure concentrations as there was no significant 'concentration $\times$ MPs size' interaction effect $\left(F_{(2,24)}=0.87, p=0.43\right)$.

Microplastics were detected in the adult stage of C. pipiens mosquitoes, and MP abundance was significantly greater under increasing initial MP exposure concentrations overall $\left(F_{(2,27)}=\right.$ $14.07, p<0.001)$ and for $2 \mu \mathrm{m}$ MP compared to $15 \mu \mathrm{m} \mathrm{MP}\left(F_{(1,26)}=4.71, p=0.04\right)$. However, we found no incidence of MP transfer at $50 \mathrm{MPs} \mathrm{mL}^{-1}$ to adults across treatments, whilst MPs were transferred to adults at $2 \mu \mathrm{m}$ MP concentrations exceeding $100 \mathrm{MPs}^{-1}$, and $15 \mu \mathrm{m}$ MP concentrations of $200 \mathrm{MPs} \mathrm{mL}^{-1}$ (Figure 1c). There were similarities across the 'concentration' and 'MPs size' interaction here $\left(F_{(2,24)}=2.09, p=0.15\right)$.

Survival to the adult stage was not significantly affected by MP concentration $\left(F_{(3,36)}=0.78, p\right.$ $=0.52$; Figure 2$)$ or by $\mathrm{MP}$ size $\left(F_{(1,35)}=0.31, p=0.58\right)$. There was no significant 'concentration $\times$ MP size' interaction effect on survival to the adult stage $\left(F_{(3,32)}=2.60, p=\right.$ $0.07)$.

Exposure concentration of MPs did not have a significant effect on the weight of adult $C$. pipiens mosquitoes $\left(F_{(3,36)}=1.46, p=0.24\right)$, and weight was not significantly influenced by 
MP size used during exposure $\left(F_{(1,35)}=0.76, p=0.39\right.$; Figure 3$)$. Similarities were observed for the interaction between 'concentration' and 'MP size' on the weight of adult C. pipiens following exposure to $\operatorname{MPs}\left(F_{(3,32)}=0.48, p=0.71\right)$.

\section{Discussion}

Microplastic pollution has increased concurrently in the aquatic environment with human population growth (Rocha-Santos and Duarte, 2014), alongside the high production and consumption of plastic materials (Andrady and Neal, 2009). Investigations have shown that the freshwater environment, including rivers, lakes and streams, contain substantial levels of microplastic pollution, with biotic impacts largely unquantified and pathways for MP dispersal poorly understood (Horton et al., 2017; Wagner and Lambert, 2018). The present study demonstrates the potential for MPs to move ontogenically from feeding larval C. pipiens mosquito complex stages, into non-feeding pupal stages, and subsequently into flying adult stages. We also show density- and size-dependence of MP uptake, with greater numbers of particles taken up where MP concentrations were higher, and MP sizes were smaller. Here, MPs did not significantly influence the survival of larval mosquitoes to the adult stage, and the size of adults was not significantly influenced by prior MP exposure.

It was no surprise to discover that mosquitoes readily ingested MPs. Larvae of Aedes aegypti (Linnaeus), Anopheles albimanus Wiedemann, Anopheles quadrimaculatus Say and Culex quinquefasciatus Say have all been shown previously to ingest polystyrene latex beads (Dadd, 1971; Aly, 1988). We show that larvae did not ingest as many of the larger $15 \mu \mathrm{m}$ MPs compared to $2 \mu \mathrm{m}$ MPs which confirms previous work that suggests that filter feeding mosquitoes ingest particles based on their own size (Merritt et al., 1992), This does not infer selection, but probably reflects physical limitations, for example first instar larvae are unable to ingest latex beads as small as $45 \mu \mathrm{m}$ in diameter (Dadd, 1971). Mosquito larvae feed using 
lateral palatal brushes to generate a current that causes water containing food or MPs to approach the mouth (Merritt et al., 1992) and it is possible that either the current or the mouth are not capable of easily dealing with larger fragments. However, MP ingestion at earlier life stages is not relevant for MPs to be passed ontogenically into the adult stage; it is only necessary for the fourth instar to ingest the plastic.

Both 2 and $15 \mu \mathrm{m}$ MPs were transferred from a feeding (larval) into a non-feeding (pupal) life stage and subsequently into the flying (adult) life stage during metamorphosis. Generally, where MPs were presented at higher concentrations, greater numbers of MPs were taken up by larval mosquitoes, and this differential abundance was sustained throughout their ontogenic development. Although MPs of both sizes were shown to transfer through to the adult stage, this transference only occurred under higher experimental concentrations (100 and 200 MPs $\left.\mathrm{mL}^{-1}\right)$. It is difficult to compare these concentrations to those in the environment since detection is often of a mixed size group of MPs; reporting varies in units used and very small MPs are often not measured (Wagner and Lambert, 2018, de Sá et al., 2018; Hurley et al., 2018).

As with Al-Jaibachi et al. (2018), we found that the MPs accumulated in the Malpighian tubules of adults, however the number of MPs was substantially less than the number of MPs in the two previous life stages. Given the exposure conditions of the present study, it is likely that depuration or excretion reduces MP concentrations over time between mosquito life stages, and particularly immediately post-emergence when adults evacuate their guts (Gillett, 1982). We suggest that MP size is a very important factor to ontogenic transfer. Small MP sizes can transfer and accumulate faster than large MPs, and in the present study smaller $2 \mu \mathrm{m}$ MPs were able to transfer to the adult stage at a lower concentration than larger $15 \mu \mathrm{m}$ MPs.

The extent to which MPs can enter new environments through metamorphosing insects is closely related to plastic toxicity; if MPs have lethal effects on immature stages, then 
transference and dispersal by adult life stages will not be possible. There was no evidence that MPs had any significant impact on the survival rate of aquatic larval C. pipiens through to the terrestrial adult stage. The absence of any negative impact on the weight of emerging adults suggests that the larvae may not have suffered from a lack of nutrition during development. Similar results have been found with studies of MP ingestion in Daphnia (Al-Jaibachi and Callaghan, 2018; Canniff and Hoang, 2018). Mosquito larval nutrition determines the extent of metabolic reserves as well as the size of adult mosquitoes upon emergence which, in turn, has a strong impact on fitness (Takken et al., 2013). Although the exposure duration was limited given that third instar larvae were used as the starting point of the experiment, the presence of MPs did not seem to influence the overall nutritional uptake of larvae to the extent where it affected adult growth. Thus, given the sustained survivability and development in the presence of MPs, it is highly likely that mosquitoes which uptake MPs will subsequently disperse MPs aerially into terrestrial food webs from the aquatic environment.

In conclusion, ontogenic transference presents a pathway for MP pollution to disperse from aquatic to terrestrial environments, vectored by mobile organisms with complex life histories. The efficacy of MP transfer is, however, dependent on both MP concentration and MP size, with considerable proportions of MPs lost between larval, pupal and adult Culex mosquito stages. Adult weights and mortality were not impacted by MPs, and so the presence of MPs does not seem to influence the viability, development or nutritional uptake of mosquitoes. Future studies should examine the effects of MPs on ontogenic transference in other aquatic insect larvae, along with a search for evidence of transference into predators. In addition, quantification of MP loss within exuviae would further elucidate the mechanism for MP reductions between ontogenic stages.

\section{Funding}


This research did not receive any specific grant from funding agencies in the public, commercial, or not-for-profit sectors. RNC is funded by a studentship through the Department for the Economy, Northern Ireland.

\section{References}

Aljaibachi, R., Callaghan, A., 2018. Impact of polystyrene microplastics on Daphnia magna mortality and reproduction in relation to food availability. PeerJ 6, e4601. https://doi.org/10.7717/peerj.4601

Aly, C., 1988. Filtration rates of mosquito larvae in suspensions of latex microspheres and yeast cells. Entomol. Exp. Appl. 46, 55-61. https://doi.org/10.1111/j.15707458.1988.tb02267.x

Andrady, A.L., Neal, M. a, 2009. Applications and societal benefits of plastics. Philos. Trans. R. Soc. Lond. B. Biol. Sci. 364, 1977-1984. https://doi.org/10.1098/rstb.2008.0304

Barnes, D.K. a, Galgani, F., Thompson, R.C., Barlaz, M., 2009. Accumulation and fragmentation of plastic debris in global environments. Philos. Trans. R. Soc. Lond. B. Biol. Sci. 364, 1985-98. https://doi.org/10.1098/rstb.2008.0205

Canniff, P.M., Hoang, T.C., 2018. Microplastic ingestion by Daphnia magna and its enhancement on algal growth. Sci. Total Environ. 633, 500-507. https://doi.org/10.1016/j.scitotenv.2018.03.176

Cole, M., Lindeque, P., Fileman, E., Halsband, C., Goodhead, R., Moger, J., Galloway, T.S., 2013. Microplastic ingestion by zooplankton. Environ. Sci. Technol. 47, 6646-6655. https://doi.org/10.1021/es400663f

Coleman, J., Juhn, J., James, A.A., 2007. Dissection of Midgut and Salivary Glands from Ae. aegypti Mosquitoes. J. Vis. Exp. 2007. https://doi.org/10.3791/228 
Crawley, M.J., 2007. The R Book, 1st ed. Wiley Publishing.

Cuthbert, R.N., Dick, J.T.A., Callaghan, A., Dickey, J.W.E., 2018. Biological control agent selection under environmental change using functional responses, abundances and fecundities; the Relative Control Potential (RCP) metric. Biol. Control 121, 50-57. https://doi.org/10.1016/j.biocontrol.2018.02.008

Dadd, R.H., 1971. Effects of Size and Concentration of Particles on Rates of Ingestion of Latex Particulates by Mosquito Larvae. Ann. Entomol. Soc. Am. 64, 687-692. https://doi.org/10.1093/aesa/64.3.687

de Sá, L.C., Oliveira, M., Ribeiro, F., Rocha, T.L., Futter, M.N., 2018. Studies of the effects of microplastics on aquatic organisms: What do we know and where should we focus our efforts in the future? Sci. Total Environ. 645, 1029-1039. https://doi.org/10.1016/j.scitotenv.2018.07.207

Dow, J. a, Maddrell, S.H., Görtz, A., Skaer, N.J., Brogan, S., Kaiser, K., 1994. The malpighian tubules of Drosophila melanogaster: a novel phenotype for studies of fluid secretion and its control. J. Exp. Biol. 197, 421-8.

Dris, R., Gasperi, J., Saad, M., Mirande, C., Tassin, B., 2016. Synthetic fibers in atmospheric fallout: A source of microplastics in the environment? Mar. Pollut. Bull. 104, 290-293. https://doi.org/10.1016/j.marpolbul.2016.01.006

Eriksen, M., Lebreton, L.C.M., Carson, H.S., Thiel, M., Moore, C.J., Borerro, J.C., Galgani, F., Ryan, P.G., Reisser, J., 2014. Plastic Pollution in the World's Oceans: More than 5 Trillion Plastic Pieces Weighing over 250,000 Tons Afloat at Sea. PLoS One 9, e111913. https://doi.org/10.1371/journal.pone.0111913

Eriksen, M., Mason, S., Wilson, S., Box, C., Zellers, A., Edwards, W., Farley, H., Amato, S., 
2013. Microplastic pollution in the surface waters of the Laurentian Great Lakes. Mar. Pollut. Bull. 77, 177-182. https://doi.org/10.1016/j.marpolbul.2013.10.007

Fischer, E.K., Paglialonga, L., Czech, E., Tamminga, M., 2016. Microplastic pollution in lakes and lake shoreline sediments - A case study on Lake Bolsena and Lake Chiusi (central Italy). Environ. Pollut. 213, 648-657. https://doi.org/10.1016/j.envpol.2016.03.012

Gillett, J.D.., 1982. Diuresis in newly emerged, unfed mosquitoes. I. Fluid loss in normal females and males during the first 20 hours of adult life. Proc. R. Soc. London. Ser. B. Biol. Sci. 216, 201 LP-207. https://doi.org/DOI: 10.1098/rspb.1982.0070

Horton, A.A., Walton, A., Spurgeon, D.J., Lahive, E., Svendsen, C., 2017. Microplastics in freshwater and terrestrial environments: Evaluating the current understanding to identify the knowledge gaps and future research priorities. Sci. Total Environ. 586, 127-141. https://doi.org/10.1016/j.scitotenv.2017.01.190

Hurley, R., Woodward, J., Rothwell, J.J., 2018. Microplastic contamination of river beds significantly reduced by catchment-wide flooding. Nat. Geosci. 11, 251-257. https://doi.org/10.1038/s41561-018-0080-1

Imhof, H.K., Ivleva, N.P., Schmid, J., Niessner, R., Laforsch, C., 2013. Contamination of beach sediments of a subalpine lake with microplastic particles. Curr. Biol. 23, R867-8. https://doi.org/10.1016/j.cub.2013.09.001

Imhof, H.K., Laforsch, C., Wiesheu, A.C., Schmid, J., Anger, P.M., Niessner, R., Ivleva, N.P., 2016. Pigments and plastic in limnetic ecosystems: A qualitative and quantitative study on microparticles of different size classes. Water Res. 98, 64-74. https://doi.org/10.1016/j.watres.2016.03.015 
Lenth, R. V, 2016. Least-Squares Means: The R Package lsmeans. J. Stat. Softw. 69, 1-33.

Macadam, C.R., Stockan, J.A., 2015. More than just fish food: Ecosystem services provided by freshwater insects. Ecol. Entomol. 40, 113-123. https://doi.org/10.1111/een.12245

Mason, S.A., Garneau, D., Sutton, R., Chu, Y., Ehmann, K., Barnes, J., Fink, P., Papazissimos, D., Rogers, D.L., 2016. Microplastic pollution is widely detected in US municipal wastewater treatment plant effluent. Environ. Pollut. 218, 1045-1054. https://doi.org/10.1016/j.envpol.2016.08.056

Mason, S.A., Welch, V., Neratko, J., 2018. Synthetic polymer contamination in bottled water. Fredonia State Univ. New York 1-17.

Merritt, R.W., Craig, D.A., Walker, E.D., Vanderploeg, H.A., Wotton, R.S., 1992. Interfacial feeding behaviour and particle flow patterns of Anopheles quadrimaculatus larvae (Diptera: Culicidae). J. Insect Behav. 5, 741-761.

Moore, C.J., 2008. Synthetic polymers in the marine environment: A rapidly increasing, longterm threat. Environ. Res. 108, 131-139. https://doi.org/10.1016/j.envres.2008.07.025

Nel, H.A., Dalu, T., Wasserman, R.J., 2018. Sinks and sources: Assessing microplastic abundance in river sediment and deposit feeders in an Austral temperate urban river system. Sci. Total Environ. 612, 950-956. https://doi.org/10.1016/j.scitotenv.2017.08.298

Qu, X., Su, L., Li, H., Liang, M., Shi, H., 2018. Assessing the relationship between the abundance and properties of microplastics in water and in mussels. Sci. Total Environ. 621, 679-686. https://doi.org/10.1016/j.scitotenv.2017.11.284

R Development Core Team, 2017. R: A Language and Environment for Statistical Computing. R Found. Stat. Comput. Vienna Austria. 
https://doi.org/10.1038/sj.hdy.6800737

Redondo-Hasselerharm, P.E., Falahudin, D., Peeters, E.T.H.M., Koelmans, A.A., 2018.

Microplastic Effect Thresholds for Freshwater Benthic Macroinvertebrates. Environ.

Sci. Technol. 52, 2278-2286. https://doi.org/10.1021/acs.est.7b05367

Rocha-Santos, T., Duarte, A.C., 2014. A critical overview of the analytical approaches to the occurrence, the fate and the behavior of microplastics in the environment. Trends Anal. Chem. 65, 47-53. https://doi.org/10.1016/j.trac.2014.10.011

Scherer, C., Brennholt, N., Reifferscheid, G., Wagner, M., 2017. Feeding type and development drive the ingestion of microplastics by freshwater invertebrates. Sci. Rep. 7, 17006. https://doi.org/10.1038/s41598-017-17191-7

Sighicelli, M., Pietrelli, L., Lecce, F., Iannilli, V., Falconieri, M., Coscia, L., Di Vito, S., Nuglio, S., Zampetti, G., 2018. Microplastic pollution in the surface waters of Italian Subalpine Lakes. Environ. Pollut. 236, 645-651.

https://doi.org/10.1016/j.envpol.2018.02.008

Su, L., Xue, Y., Li, L., Yang, D., Kolandhasamy, P., Li, D., Shi, H., 2016. Microplastics in Taihu Lake, China. Environ. Pollut. 216, 711-719. https://doi.org/10.1016/j.envpol.2016.06.036

Sussarellu, R., Suquet, M., Thomas, Y., Lambert, C., Fabioux, C., Pernet, M.E.J., Le Goïc, N., Quillien, V., Mingant, C., Epelboin, Y., Corporeau, C., Guyomarch, J., Robbens, J., Paul-Pont, I., Soudant, P., Huvet, A., 2016. Oyster reproduction is affected by exposure to polystyrene microplastics. Proc. Natl. Acad. Sci. 113, 2430-2435. https://doi.org/10.1073/pnas.1519019113

Takken, W., Smallegange, R.C., Vigneau, A.J., Johnston, V., Brown, M., Mordue-Luntz, 
A.J., Billingsley, P.F., 2013. Larval nutrition differentially affects adult fitness and Plasmodium development in the malaria vectors Anopheles gambiae and Anopheles stephensi. Parasites and Vectors 6, 345. https://doi.org/10.1186/1756-3305-6-345

Townroe, S., Callaghan, A., 2015. Morphological and fecundity traits of Culex mosquitoes caught in gravid traps in urban and rural Berkshire, UK. Bull. Entomol. Res. 105, 615620. https://doi.org/10.1017/S000748531500053X

Vaughan, R., Turner, S.D., Rose, N.L., 2017. Microplastics in the sediments of a UK urban lake. Environ. Pollut. 229, 10-18. https://doi.org/10.1016/j.envpol.2017.05.057

Wagner, M., Lambert, S., 2018. Freshwater Microplastics, The Handbook of Environmental Chemistry. Springer International Publishing, Cham. https://doi.org/10.1007/978-3-319$61615-5$

Watts, A.J.R., Lewis, C., Goodhead, R.M., Beckett, S.J., Moger, J., Tyler, C.R., Galloway, T.S., 2014. Uptake and Retention of Microplastics by the Shore Crab Carcinus maenas. Environ. Sci. Technol. 
Figure 1. The number of microplastics (MP) across different exposure concentrations $(50,100$ and $200 \mathrm{MPs} \mathrm{mL}^{-1}$ ) and sizes (2 and $15 \mu \mathrm{m}$ ) in (a) larval stage, (b) pupal stage and (c) adult stage Culex pipiens. Means are \pm SE.

Figure 2. Mortality rates between larval and adult stage of Culex pipiens exposed to MPs under different concentrations $\left(0,50,100\right.$ and $\left.200 \mathrm{MPs} \mathrm{mL}^{-1}\right)$ and of different sizes $(2$ and $15 \mu \mathrm{m})$. Means are \pm SE.

Figure 3. Weights of emerging Culex pipiens adults following exposure to MPs of different concentrations $\left(0,50,100\right.$ and $\left.200 \mathrm{MPs} \mathrm{mL}^{-1}\right)$ and sizes $(2$ and $15 \mu \mathrm{m})$. Means are $\pm \mathrm{SE}$.

$\mathrm{mL}^{-1}$ 